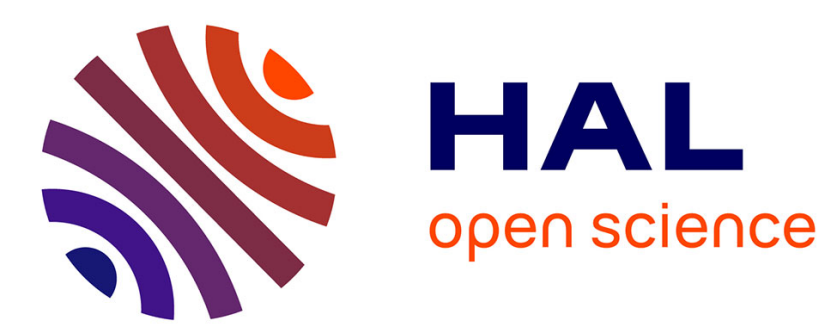

\title{
The birth and life of lipid droplets: learning from the hepatitis $\mathrm{C}$ virus.
}

Philippe Roingeard, Marion Depla

\section{To cite this version:}

Philippe Roingeard, Marion Depla. The birth and life of lipid droplets: learning from the hepatitis C virus.: Lipid droplets in HCV infection. Biology of the Cell, 2011, 103 (5), pp.223-31. 10.1042/BC20100119 . inserm-00664942

\section{HAL Id: inserm-00664942 https://www.hal.inserm.fr/inserm-00664942}

Submitted on 31 Jan 2012

HAL is a multi-disciplinary open access archive for the deposit and dissemination of scientific research documents, whether they are published or not. The documents may come from teaching and research institutions in France or abroad, or from public or private research centers.
L'archive ouverte pluridisciplinaire HAL, est destinée au dépôt et à la diffusion de documents scientifiques de niveau recherche, publiés ou non, émanant des établissements d'enseignement et de recherche français ou étrangers, des laboratoires publics ou privés. 
Biol Cell. 2011 May;103(5):223-231. Review.

\section{The birth and life of lipid droplets: learning from the hepatitis $\mathbf{C}$ virus}

\section{Philippe Roingeard* and Marion Depla}

INSERM U966, Université François Rabelais and CHRU de Tours, 10 Boulevard Tonnellé, 37032 Tours, France

Running title: Lipid droplets in HCV infection

*To whom correspondence should be adressed :

Laboratoire de Biologie Cellulaire

INSERM U966

Faculté de Médecine, Université François Rabelais

10 Boulevard Tonnellé, 37032 Tours, France

Tel: (33) 234379646

Fax: (33) 247366090

email : roingeard@med.univ-tours.fr

Key words: Lipid droplet, organelle dynamics, hepatitis C virus.

Abbreviations used : DGAT1, diacylglycerol acyltransferase-1; DGAT2, diacylglycerol acyltransferase-2; HCV, hepatitis C virus; LD, lipid droplet; TEM, transmission electron microscopy. 


\begin{abstract}
Lipid droplets are probably the least well characterised cellular organelles. Having long been considered simple lipid storage depots, they are now considered to be dynamic organelles involved in many biological processes. However, most of the mechanisms driving lipid droplets biogenesis, growth and intracellular movement remain largely unknown. As for other cellular mechanisms deciphered through the study of viral models, hepatitis $\mathrm{C}$ virus $(\mathrm{HCV})$ is an original and relevant model for investigations of the birth and life of these organelles. Recent studies in this model have raised the hypothesis that the HCV core protein induces the redistribution of lipid droplets through the regression and regeneration of these organelles in specific intracellular domains.
\end{abstract}

\title{
Introduction
}

Cytoplasmic lipid droplets (LD) are intracellular structures that store neutral lipids. Until recently, they were classified in the same category as glycogen granules, as simple inert storage sites for energy, increasing and decreasing as a function of metabolic energy requirements. However, considerable interest has recently been focused on LDs as dynamic organelles at the hub of lipid exchanges between intracellular compartments and energy metabolism (Martin and Parton, 2006; Murphy et al., 2009). Major findings highlighting the dynamic nature of LDs include the identification of key proteins involved in LD biology and the discovery of differences in the protein and lipid compositions of LDs in different cell types and physiological states (Bickel et al., 2009). There is also increasing evidence to suggest that LDs interact dynamically with other membrane-bound organelles, including the endoplasmic reticulum (ER), mitochondria, endosomes, peroxisomes and the plasma membrane, probably as a means of providing these organelles with neutral lipids and phospholipids (Goodman 2008 ; Murphy et al., 2009). More intriguingly, LDs have also been shown to have a number of unexpected functions such as constituting a protective reservoir for unfolded proteins or other compounds unrelated to lipids to prevent harmful interactions with other cell components (Ohsaki et al., 2006 ; Welte 2007).

However, despite rapid progress in LD research, the mechanisms underlying the formation and dynamics of LDs remain elusive. Recent studies on hepatitis C virus (HCV), an important human pathogen, have demonstrated that HCV uses LDs as a platform for viral 
assembly (Miyanari et al., 2007). This phenomenon is linked to the ability of the HCV core protein to induce the redistribution of LDs, through the clustering of these organelles in the perinuclear area (Boulant et al., 2008 ; Depla et al., 2010). Many other cellular mechanisms have already been deciphered by studying viruses, and HCV may be a relevant model for elucidating the birth and life of LDs.

\section{LD morphology and composition}

Although best known for their role in lipid storage in mammalian adipocytes in adipose tissue, LDs are present in almost all eukaryotic cells, including yeasts, and even in some prokaryotes. Unlike vesicular organelles, the aqueous contents of which are enclosed by a phospholipid bilayer, LDs consist of a highly hydrophobic lipid core surrounded by a phospholipid monolayer (Murphy and Vance 1999; Tauchi-Sato et al., 2002). On transmission electron microscopy (TEM) analysis of conventional ultrathin sections, LDs are visible as spherical structures with a highly homogeneous content (Fig. 1A).

LDs store neutral lipids, predominantly triglycerides and sterol esters. These substances are crucial for the cell. Triglycerides are the principle compounds used for energy storage, and both triglycerides and sterol esters serve as reservoirs of membrane lipid components. Adipocytes contain mostly triglycerides whereas macrophages contain mostly sterol esters. Ether-linked glycerolipids also account for 10 to $20 \%$ of the lipids in several cultured cell lines (Bartz et al., 2007a). The phospholipids forming the monolayer, with their inward-pointing acyl chains, are essentially very similar to those found in the ER (Bartz et al., 2007a). However, different proteins are present on the surface of LDs. Perilipin, which is found in adipose tissues, is one of the best studied proteins associated with LDs (Greenberg et al., 1991). Perilipin stabilises the LDs and is also essential for lipolysis, becoming highly phosphorylated upon adrenergic stimulation, thereby attracting hormone-sensitive lipase to the LD (Sztalryd et al., 2003). However, perilipin belongs to a larger family of animal LDbinding proteins, all containing the PAT domain, named after the three founding members of this family: perilipin, adipophilin (or ADRP, for adipose differentiation-related protein) and TIP 47 (for tail interacting protein of $47 \mathrm{kDa}$ ). More recently, a new nomenclature leading to the name of PLIN proteins has been established for the mammalian PAT-proteins (Kimmel et al., 2010). Each PAT/PLIN protein has unique tissue and subcellular distributions, and LDbinding properties consistent with a unique role in LD content management (Goodman 2008). Some of these proteins are exchangeable at the surface of LDs in various conditions and regulate the storage of lipids within the cell (Wolins et al., 2006; Bickel et al., 2009). 
Individual cells may also contain subsets of LDs with different populations of PAT/PLIN proteins, varying with size, age and the level of metabolic activity (Wolins et al., 2006; Brasaemle et al., 2007; Digel et al., 2010).

LDs have been subject to many proteomic studies in recent years (Bartz et al., 2007b ; Hodges and $\mathrm{Wu} 2010)$. These studies unexpectedly picked up proteins regulating trafficking pathways, such as members of both the Rab and ADP-ribosylation factor (ARF) families of small GTPases, caveolin, and other proteins thought to be specific for vesicle docking events in exocytosis pathways. Of the potentially LD-associated Rab proteins, only a limited number have been examined in detail in the context of the LD. However, Rab18 has received particular attention because it shows specific regulated localisation to the surface of LDs (Ozeki et al., 2005, Martin et al., 2005). The identification of these proteins on LDs provides evidence for a role for LDs in communications between organelles (Zehmer et al., 2009a). In addition, motor proteins, such as dynein and kinesin, have been identified in some LDs, suggesting on the possible movement of these structures on microtubules during the transfer of molecules to various organelles (Zehmer et al., 2009a).

\section{LD formation}

There is considerable evidence to indicate that LDs are derived from the ER. TEM studies have revealed that LDs are tightly associated with the ER membrane (Fig. 1B), and proteomic studies of LDs isolated from various cell lines have revealed the presence of many ER proteins (Liu et al., 2004; Brasaemle et al., 2004; Wan et al., 2007). It has been suggested that LDs associated intimately with the ER, with the ER membrane forming a structure resembling an egg cup and holding the LD, which resembles an egg (Robenek et al., 2006). However, the prevailing model for LD formation involves the emergence of LDs from the ER lipid bilayer as a lens-shaped mass of neutral lipids that then buds off from the cytoplasmic face of the bilayer to form a droplet within the cytoplasm (Brasaemle 2007; Wolins et al., 2006). It has been suggested that exchangeable PAT/PLIN proteins curve the ER membrane to mediate this budding, acting as coatamer-like proteins (Wolins et al., 2006). This model is attractive because it accounts for the phospholipid monolayer surrounding LDs and localises the birthplace of LDs to the organelle in which the enzymes mediating neutral lipid synthesis are found on biochemical analysis. Moreover, the diacylglycerol acyltransferase-2 (DGAT2), a key enzyme involved in triglyceride synthesis, is found in areas in which LD are tightly associated with the ER, under conditions promoting LD formation (Kuerschner et al., 2008). There is some evidence to suggest that LDs never leave the ER, instead constituting 
specialised regions of the ER. TEM studies have frequently shown continuity between the cytosolic leaflet of the ER and the boundary leaflet of the LDs (Blanchette-Mackie et al., 1995). Moreover, three-dimensional reconstructions of large cellular domains have shown that LDs are invariably intimately linked to the ER compartment (Fig. 1B; see also the QuickTime movie of a 3D reconstruction of such large microdomain, provided online as supplemental material). This notion that LDs are specialised regions of the ER is attractive because this organisation would provide a simple mechanism for the exchange of lipids and proteins between these two compartments. For example, during metabolic stress requiring the rapid hydrolysis of esterified fatty acids and the release of free fatty acids, the leaflet must rapidly shrink. Continuity with the ER would make it possible for this compartment to act as a sink for these leaflet components (Goodman 2008). Alternatively, there is evidence to suggest that the trafficking of membrane-derived vesicles may connect the ER with LDs that have been fully released from the ER membrane (Farese and Walther 2009). However, this model cannot account for the fusion of vesicles surrounded by a bilayer membrane with the monolayer surrounding LDs. In addition, many of the proteins identified in the LD proteome are predicted to have multiple membrane spans and it is difficult to imagine them arranged in a single leaflet surrounding a hydrophobic core of neutral lipids (Goodman 2009). These observations suggest that these proteins are more likely to be present in specialised ER membranes tightly bound to the LD that could be separated from the bulk ER during fractionation, thus being purified with the LD. However, this model remains speculative and caution should be employed when using it as a basis for other hypotheses.

\section{LD growth and mobilization}

LD size varies tremendously, from a diameter of only 50 to $100 \mathrm{~nm}$ to a diameter of $100 \mu \mathrm{m}$ in white adipocytes. LD can also clearly grow in size. It is possible that LDs expand as single organelles, like inflated balloons. If LDs remain physically attached to the ER, proteins and newly synthesised lipids could diffuse laterally into the LDs. If LDs are fully detached from the ER, these proteins and lipids must be transported to the LDs in vesicles, although the topological problems arising from the fusion of a vesicular bilayer membrane with the monolayer membrane at the surface of LD suggest that this is unlikely. Alternatively, the neutral lipids in the LD core may be produced locally by enzymes such as DGAT2, which is present on the surface of LDs (Kuerschner et al, 2008). However, any such increase in the volume of neutral lipids would need to be matched by a corresponding increase of the synthesis of phospholipids at the surface of LD. The recent demonstration that key enzymes 
required for phospholipid synthesis are present at the LD surface provides support for this potential mechanism (Guo et al., 2008).

The fusion of several smaller LDs to form larger LDs may also contribute to LD growth (Guo et al., 2008), and models in which SNARE proteins and motor proteins are involved in LD fusion have been proposed (Andersson et al, 2006; Boström et al., 2007; Olofsson et al., 2008; Ducharme and Bickel 2008). However, due to the extremely low frequency of this phenomenon in live imaging, LD fusion remains a controversial subject (Thiele and Spandl 2008; Farese and Walther 2009; Cheng et al., 2009; Murphy et al., 2010). Indeed, it has been pointed out that LD fusion is not observed in situations in which LD are densely packed such that there are obvious signs of mechanical strain, with LDs being pressed against each other (Thiele and Spand1 2008). This is remarkable, given that LDs have only a monolayer membrane, so their fusion would therefore require only one simple step. It has also been argued that the small amount of protein recovered from LD preparations is consistent with the absence of a dense coverage of proteins with anti-fusion activities on the surface of LDs (Thiele and Spandl 2008). It therefore seems possible that the composition of the LD monolayer may contribute to the inhibition of spontaneous fusion. Moreover, LD fusion would generate a large excess of phospholipids originating from the surface of the small original LDs, and it is unclear how the large LD formed by fusion could simultaneously adjust its phospholipid monolayer (Ohsaki et al., 2009).

LDs not only grow, they may also shrink through lipolysis induced by the lipases present at the LD surface. The proteins of the PAT/PLIN family play a key role in the organisation and regulation of this process (Brasaemle 2007). More recently, it has been shown that autophagy induced by nutrient deprivation (Singh et al., 2009) or dengue virus infection (Heaton and Randall 2010) may also regulate the mobilization of lipids from LDs. In adipocytes, it has been suggested that LDs may undergo fission during lipolysis. This would greatly increase the surface area of LDs, improving the access of lipases to the neutrallipid core (Marcinkiewicz et al., 2006). However, this increase in surface area would require more surface phospholipids and the mechanism by which this could be achieved remains unclear. It therefore appears most likely that LDs are never completely severed from the ER, instead remaining permanently connected to the outer leaflet of the ER membrane. Pioneer TEM observations have suggested that LDs accumulate or regress within the confines of ER membranes (Blanchette-Mackie et al., 1995). More recent studies have also provided support for this model by demonstrating experimentally that LDs are formed from and regress to the 
ER as part of a cyclic process that does not involve trafficking through the secretory pathway (Zehmer et al., 2009b).

\section{Intracellular movements of LD}

Live imaging has shown that LDs move around the cytoplasm in many cells. In some cases, the distribution of the entire population of LDs in cells may change dramatically within a few hours (Welte 2009). This mobility seems to involve mostly microtubule-based transport. The pharmacological disruption of microtubules typically prevents this movement of LDs, whereas the disruption of actin filaments has little effect. Moreover, cytoplasmic dynein, a minus end-directed microtubule motor, is often physically associated with LDs, and the functional inactivation of dynein prevents LDs from moving within the cell in various models (Welte 2009). Although it is tempting to speculate that these changes are due to LDs moving along the microtubules from one location in the cell to another, as suggested by some movies, other interpretations have been considered. It has also been suggested (Welte 2009) that LDs may not move as a unit, instead regressing and being regenerated at their destination. The requirement of dynein as a co-factor for the formation of a nascent LD is consistent with this hypothesis (Andersson et al., 2006). This process would involve lipids from shrinking LDs diffusing laterally through the expansive ER network to form new LDs elsewhere in the cell (Murphy et al, 2009; Welte 09).

\section{The hepatitis $\mathrm{C}$ virus model}

$\mathrm{HCV}$ infection is rapidly becoming a major global health issue, with more than 130 million people infected worldwide (Alter 2007). Of those exposed to $\mathrm{HCV}, 80 \%$ become chronically infected, and at least $30 \%$ of carriers go on to develop severe liver diseases such as cirrhosis and liver carcinoma. There is currently no vaccine to prevent new infections and the efficacy of current therapies remains limited. In recent years, the impact of HCV infection on lipid metabolism and in particular the development of a liver steatosis has emerged as a clinically important topic in liver diseases (Roingeard and Hourioux 2008; Piver et al., 2010). HCV has a positive-sense, single-stranded RNA genome encoding a single polyprotein that is both coand post-translationally cleaved at the ER membrane by host or viral proteases to generate several proteins (Moradpour et al., 2007). The N-terminal component of the polyprotein encodes the structural proteins: the core protein, which forms the viral capsid, and the two envelope proteins that surround the capsid to form the virion. The C-terminal region of the 
polyprotein contains the non-structural (NS) proteins involved in the formation of replication complexes for the synthesis of viral RNA (Moradpour et al., 2007).

Many years before a tissue culture system for producing infectious HCV in vitro had been developed, the HCV core protein was reported to be associated with the surface of LDs (Moradpour et al., 1996 ; Barba et al., 1997). This association is dependent on the release of the protein from the polyprotein by two different cellular proteases: signal peptidase (SP) and signal peptide peptidase (SPP) (McLauchlan et al., 2002). SP cleaves the polyprotein at the Cterminus of a signal peptide between the core and envelope proteins, producing an immature form of the core protein that is unable to associate with LDs. The second cleavage, by SPP, occurs within the signal peptide and generates the mature form of the protein, which is then transported toward the LD surface (McLauchlan et al., 2002). During this trafficking step, the $\mathrm{HCV}$ core protein remains attached to the ER cytosolic monolayer membrane and then to the monolayer membrane surrounding the LD, through its C-terminal domain, which probably interacts in-plane with these membranes (McLauchlan 2009a). Following the long-awaited successful propagation of an HCV strain in cultured hepatic Huh7 cells, it has recently been shown that LDs are directly involved in the production of infectious HCV particles (Miyanari et al., 2007). This study demonstrated that the HCV core protein on LDs recruits nonstructural proteins and replicated RNA to LD-associated membranes, and that this structural arrangement plays a crucial role in the formation of infectious viruses. Disruption of the association of HCV core protein with LDs was found to cause a defect in the localisation of HCV RNA and non-structural proteins to regions surrounding LDs, thereby preventing infectious virus assembly (Miyanari et al., 2007 ; Boulant et al., 2007). Further investigations with this infectious HCV system demonstrated that HCV core protein initially attached to a discrete site on LDs after processing by SPP, subsequently coating the entire LD (Boulant et al., 2007). This observation suggested that there might be a defined loading site for the core protein, probably at points of contacts between LDs and the ER membrane (Boulant et al., 2007). More recently, it has been demonstrated that a key enzyme involved in triglyceride synthesis, the diacylglycerol acyltransferase-1 (DGAT1), is involved in the HCV infectious cycle. Both DGAT1 and DGAT2 are ER resident enzymes that catalyze the final step in triglyceride biosynthesis and are essential in LD biogenesis, but only DGAT2 remains associated with the LDs. Recent studies have demonstrated that DGAT1 interacts with the $\mathrm{HCV}$ core protein and promotes its traffic to the surface of DGAT1-generated LDs (Herker et al., 2010). It remains unclear why HCV targets LDs, but this targeting may be linked to the contribution of these LDs to the formation of very-low-density lipoproteins (VLDLs) in 
hepatocytes, as the viruses circulating in chronically infected patients are associated with lipoproteins (André et al., 2002; Icard et al., 2009; McLauchlan 2009b).

Nevertheless, one of the key elements underlying the production of infectious virions is the modification of LD distribution within cells by HCV core protein, such that LDs tend to aggregate in the perinuclear area (Boulant et al., 2008; Roingeard et al., 2008). This redistribution of LDs may lead to the close apposition of LDs with sites of viral RNA replication containing newly synthesised viral genomes and the non-structural proteins (Boulant et al., 2008). HCV RNA is replicated at perinuclear ER-derived membranes known as the membranous web (Moradpour et al., 2003), and the clustering of LDs around these membranes is thought to increase the likehood of interaction between the HCV core protein and the newly synthesised RNA, thereby promoting genome packaging, the first step in virus assembly. Light microscopy studies demonstrated that the LD clustering induced by the HCV core protein was blocked by disrupting the microtubule network or impairing dynein function (Boulant et al., 2008 ; Lyn et al., 2010). The authors naturally interpreted these results as indicating a redistribution of the pre-existing LDs through the trafficking of these organelles along the microtubule network and toward the centrosome. However, analyses of this phenomenon by conventional or three-dimensional TEM have shown that the aggregating LDs are much larger that the pre-existing LDs, and do not preferentially cluster in the centrosome area (Depla et al., 2010). In addition, aggregated LDs have been shown to emerge from ER membranes rich in HCV core protein (Depla et al., 2010; Fig 2). This suggests that these aggregated LDs surrounded by the $\mathrm{HCV}$ core protein budded from specific ER membranes enriched in HCV core protein, consistent with the LD regression/regeneration hypothesis outlined above (Fig 3). Indeed, it seems unlikely that LDs dispersed throughout the cytoplasm would move specifically towards these areas with a core-rich ER membrane. It remains unclear whether the HCV core protein is actively involved in lipid mobilization, membrane curvature and LD budding, as suggested for PAT/PLIN proteins (Wolins et al., 2006; Listenberger et al., 2007) However, the HCV core protein has been shown to displace ADRP, like other exchangeable PAT/PLIN proteins (Boulant et al., 2008). Although some studies have suggested that the same LD may experience a gradual exchange of PAT/PLIN proteins (Wolins et al., 2005), the LD regression/regeneration hypothesis would also provide a comprehensive model accounting for the replacement of ADRP by the HCV core protein in newly synthesised LDs (Fig 3). Interestingly, LD clustering has also been observed in other cellular models, without HCV infection. In some cases, the degree of LD clustering seemed to depend on the metabolic state, with lipolysis counteracting clustering (Marcinkiewicz et al., 
2006). In the yeast model, the absence of seipin, a LD-associated protein, resulted in a LD clustering (Szymanski et al., 2007). In contrary, overexpression of various PAT/PLIN proteins may also lead to LD clustering (Targett-Adams et al., 2003; Listenberger et al., 2007). Altogether, these results suggest that the replacement of a given LD-associated protein by one or others LD-associated proteins could induce this intracellular relocalisation of LDs. This reinforces the hypothesis that, following their biogenesis, LDs remain tethered to the ER membrane, allowing the exchange of proteins between the LD surface to occur.

\section{Conclusion and perspectives}

Intracellular LDs have gone from being largely ignored as static cytoplasmic inclusions to being actively studied as dynamic organelles regulating not only cellular lipid storage, but also lipid exchange with various organelles. However, several fundamental questions about the biology of LDs remain unanswered. In particular, we still know little about the process by which they are formed. The HCV core protein, which seems able to induce the rapid regression and regeneration of cytoplasmic LDs, is a potentially valuable model for the visualisation of LD morphogenesis by correlative fluorescence/electron microscopy during the first few minutes of LD formation. We need to determine whether the regression and regeneration of LDs that seems to be induced by the HCV core protein is a widespread mechanism of LD motion also occurring in other contexts. It should be reminded that movies provided as supplemental material of several published manuscripts have shown that at least some LDs remained intact throughout the period of movement between regions of the cells. Future investigation should help to understand the highly regulated, integrated and strongly compartmentalised cellular network of metabolism, signalling and trafficking leading to LD formation and degradation.

\section{Acknowledgments}

Research on HCV and LD interactions in our laboratory is supported by grants from INSERM-DHOS and Ligue Contre le Cancer (Comité du Loir et Cher \& Comité de l'Ille et Vilaine). M.D. was supported by a Ph.D fellowship provided by INSERM, Région Centre, and the Fondation pour la Recherche Médicale (FRM). Our TEM photographs are obtained with the assistance of the RIO EM Facility of François Rabelais University. 


\section{References}

Alter, M. J. (2007) Epidemiology of hepatitis C virus infection. World J. Gastroenterol. 13, 2436-2441.

Andersson, L., Boström, P., Ericson, J., Rutberg, M., Magnusson, B., Marchesan, D., Ruiz, M., Asp, L., Huang, P., Frohman, M. A., Boren, J., Olofsson, S.O. (2006) PLD1 and ERK2 regulate cytosolic lipid droplet formation. J. Cell. Sci. 119, 2246-2257.

André, P., Komurian-Pradel, F., Deforges, S., Perret, M., Berland, J. L., Sodoyer, M., Pol, S., Bréchot, C., Paranhos-Baccalà, G., and Lotteau, V. (2002) Characterization of low- and very-low-density hepatitis C virus RNA-containing particles. J. Virol. 76, 6919-6928.

Barba, G., Harper, F., Harada, T., Kohara, M., Goulinet, S., Matsuura, Y., Eder, G., Schaff, Z., Chapman, M. J., Miyamura, T., Brechot, C. (1997) Hepatitis C virus core protein shows a cytoplasmic localization and associates to cellular lipid storage droplets. Proc. Natl. Acad. Sci. USA 94, 1200-1205.

Bartz, R., Li, W., Venables, B., Zehmer, J. K., Roth, M. R., Welti, R., Anderson, R. G. W., Liu, P., and Chapman, K. D. (2007a) Lipidomics reveals that adiposomes store ether lipids and mediate phospholipid traffic. J. Lipid Res. 48, 837-847.

Bartz, R., Zehmer, J. K., Zhu, M., Chen, Y., Serrero, G., Zhao, Y., and Liu, P. (2007b) Dynamic activity of lipid droplets: protein phosphorylation and GTP-mediated protein translocation. J. Proteome Res. 6, 3256-3265.

Bickel, P. E., Tansey, J. T., and Welte, M. A. (2009) PAT proteins, an ancient family of lipid droplet proteins that regulate cellular lipid stores. Biochim. Biophys. Acta 1791, 419-440.

Blanchette-Mackie, E. J., Dwyer, N. K., Barber, T., Coxey, R. A., Takeda, T., Rondinone, C. M., Theodorakis, J. L., Greenberg, A. S., and Londos, C. (1995) Perilipin is located on the surface layer of intracellular lipid droplets in adipocytes. J. Lipid Res. 36, 1211-1226.

Boström, P., Andersson, L., Rutberg, M., Perman, J., Lidberg, U., Johansson, B. R., Fernandez-Rodriguez, J., Ericson, J., Nilsson, T., Borén, J., Olofsson, S.O. (2007) SNARE proteins mediate fusion between cytosolic lipid droplets and are implicated in insulin sensitivity. Nat. Cell Biol. 9, 1286-1293.

Boulant, S., Targett-Adams, P., and McLauchlan, J. (2007) Disrupting the association of hepatitis $\mathrm{C}$ virus core protein with lipid droplets correlates with a loss in production of infectious virus. J. Gen. Virol. 88, 2204-2213. 
Boulant, S., Douglas, M. W., Moody, L., Budkowska, A., Targett-Adams, P., and McLauchlan, J. (2008) Hepatitis C virus core protein induces lipid droplet redistribution in a microtubule- and dynein-dependent manner. Traffic 9, 1268-1282.

Brasaemle, D. L. (2007) The perilipin family of structural lipid droplet proteins: stabilization of lipid droplets and control of lipolysis. J. Lipid Res. 48, 2547-2559.

Brasaemle, D. L., Dolios, G., Shapiro, L., and Wang, R. (2004) Proteomic analysis of proteins associated with lipid droplets of basal and lipolytically stimulated 3T3-L1 adipocytes. J. Biol. Chem. 279, 46835-46842.

Cheng, J., Fujita, A., Ohsaki, Y., Suzuki, M., Shinohara, Y., and Fujimoto, T. (2009) Quantitative electron microscopy shows uniform incorporation of triglycerides into existing lipid droplets. Histochem. Cell Biol. 132, 281-291.

Depla, M., Uzbekov, R., Hourioux, C., Blanchard, E., Le Gouge, A., Gillet, L., and Roingeard, P. (2010) Ultrastructural and quantitative analysis of the lipid droplet clustering induced by hepatitis C virus core protein. Cell Mol. Life Sci. 67, 3151-3161.

Digel, M., Ehehalt, R., and Füllekrug, J. (2010) Lipid droplets lighting up: insights from live microscopy. FEBS Lett. 584, 2168-2175.

Ducharme, N. A. and Bickel, P. E. (2008) Lipid droplets in lipogenesis and lipolysis. Endocrinology 149, 942-949.

Farese, R. V. and Walther, T. C. (2009) Lipid droplets finally get a little R-E-S-P-E-C-T. Cell 139, $855-860$.

Goodman, J. M. (2008) The gregarious lipid droplet. J. Biol. Chem. 283, 28005-28009.

Goodman, J. M. (2009) Demonstrated and inferred metabolism associated with cytosolic lipid droplets. J. Lipid Res. 50, 2148-2156.

Greenberg, A. S., Egan, J. J., Wek, S. A., Garty, N. B., Blanchette-Mackie, E. J., and Londos, C. (1991) Perilipin, a major hormonally regulated adipocyte-specific phosphoprotein associated with the periphery of lipid storage droplets. J. Biol. Chem. 266, 11341-11346.

Guo, Y., Walther, T. C., Rao, M., Stuurman, N., Goshima, G., Terayama, K., Wong, J. S., Vale, R. D., Walter, P., and Farese, R. V. (2008) Functional genomic screen reveals genes involved in lipid-droplet formation and utilization. Nature 453, 657-661.

Heaton, N.S., and Randall, G. (2010) Dengue virus-induced autophagy regulates lipid metabolism. Cell Host Microbe 8, 422-432.

Herker, E., Harris, C., Hernandez, C., Carpentier, A., Kaehlcke, K., Rosenberg, A.R., Farese, R.V., and Ott, M. Efficient hepatitis $\mathrm{C}$ virus particle formation requires diacylglycerol acyltransferase-1. Nat. Med. 16, 1295-1298. 
Hodges, B. D. M. and Wu, C. C. (2010) Proteomic insights into an expanded cellular role for cytoplasmic lipid droplets. J. Lipid Res. 51, 262-273.

Icard, V., Diaz, O., Scholtes, C., Perrin-Cocon, L., Ramière, C., Bartenschlager, R., Penin, F., Lotteau, V., and André, P. (2009) Secretion of hepatitis C virus envelope glycoproteins depends on assembly of apolipoprotein B positive lipoproteins. PLoS ONE 4, e4233.

Kimmel, A.R., Brasaemle, D.L., McAndrew-Hill, M., Sztalryd, C., and Londos, C. (2010) Adoption of perilipin as a unifying nomenclature for the mammalian PAT-family of intracellular lipid storage droplet proteins. J. Lipid. Res. 51, 468-471.

Kuerschner, L., Moessinger, C., and Thiele, C. (2008) Imaging of lipid biosynthesis: how a neutral lipid enters lipid droplets. Traffic 9, 338-352.

Listenberger, L. L., Ostermeyer-Fay, A. G., Goldberg, E. B., Brown, W. J., and Brown, D. A. (2007) Adipocyte differentiation-related protein reduces the lipid droplet association of adipose triglyceride lipase and slows triacylglycerol turnover. J. Lipid Res. 48, 27512761.

Liu, P., Ying, Y., Zhao, Y., Mundy, D. I., Zhu, M., and Anderson, R. G. W. (2004) Chinese hamster ovary K2 cell lipid droplets appear to be metabolic organelles involved in membrane traffic. J. Biol. Chem. 279, 3787-3792.

Lyn, R. K., Kennedy, D. C., Stolow, A., Ridsdale, A., and Pezacki, J. P. (2010) Dynamics of lipid droplets induced by the hepatitis $\mathrm{C}$ virus core protein. Biochem. Biophys. Res. Commun. 339, 518-524.

Marcinkiewicz, A., Gauthier, D., Garcia, A., and Brasaemle, D. L. (2006) The phosphorylation of serine 492 of perilipin a directs lipid droplet fragmentation and dispersion. J. Biol. Chem. 281, 11901-11909.

Martin, S., Driessen, K., Nixon, S.J., Zerial, M., Parton, R.G. (2005) Regulated localization of Rab18 to lipid droplets: effect of lipolytic stimulation and inhibition of lipid droplet catabolism. J. Biol. Chem. 280, 42325-42335.

Martin, S. and Parton, R. G. (2006) Lipid droplets: a unified view of a dynamic organelle. Nat. Rev. Mol. Cell Biol. 7, 373-378.

McLauchlan, J. (2009a) Lipid droplets and hepatitis C virus infection. Biochim. Biophys. Acta 1791, 552-559.

McLauchlan, J. (2009b) Hepatitis C virus: viral proteins on the move. Biochem. Soc. Trans. 37, 986-990. 
McLauchlan, J., Lemberg, M. K., Hope, G., and Martoglio, B. (2002) Intramembrane proteolysis promotes trafficking of hepatitis $\mathrm{C}$ virus core protein to lipid droplets. $\mathrm{EMBO}$ J. 21, 3980-3988.

Miyanari, Y., Atsuzawa, K., Usuda, N., Watashi, K., Hishiki, T., Zayas, M., Bartenschlager, R., Wakita, T., Hijikata, M., and Shimotohno, K. (2007) The lipid droplet is an important organelle for hepatitis C virus production. Nat. Cell Biol. 9, 1089-1097.

Moradpour, D., Englert, C., Wakita, T., and Wands, J. R. (1996) Characterization of cell lines allowing tightly regulated expression of hepatitis $\mathrm{C}$ virus core protein. Virology $\mathbf{2 2 2}, 51$ 63.

Moradpour, D., Gosert, R., Egger, D., Penin, F., Blum, H. E., and Bienz, K. (2003) Membrane association of hepatitis $\mathrm{C}$ virus nonstructural proteins and identification of the membrane alteration that harbors the viral replication complex. Antiviral Res. 60, 103-109.

Moradpour, D., Penin, F., and Rice, C. M. (2007) Replication of hepatitis C virus. Nat. Rev. Microbiol. 5, 453-463.

Murphy, D. J. and Vance, J. (1999) Mechanisms of lipid-body formation. Trends Biochem. Sci. 24, 109-115.

Murphy, S., Martin, S., and Parton, R. G. (2009) Lipid droplet-organelle interactions; sharing the fats. Biochim. Biophys. Acta 1791, 441-447.

Murphy, S., Martin, S., and Parton, R. G. (2010) Quantitative analysis of lipid droplets fusion : innefficient steady state fusion but rapid stimulation by chemical fusogens. PloS One 5, e15030.

Ohsaki, Y., Cheng, J., Fujita, A., Tokumoto, T., and Fujimoto, T. (2006) Cytoplasmic lipid droplets are sites of convergence of proteasomal and autophagic degradation of apolipoprotein B. Mol. Biol. Cell 17, 2674-2683.

Ohsaki, Y., Cheng, J., Suzuki, M., Shinohara, Y., Fujita, A., and Fujimoto, T. (2009) Biogenesis of cytoplasmic lipid droplets: from the lipid ester globule in the membrane to the visible structure. Biochim. Biophys. Acta 1791, 399-407.

Olofsson, S., Boström, P., Andersson, L., Rutberg, M., Levin, M., Perman, J., and Borén, J. (2008) Triglyceride containing lipid droplets and lipid droplet-associated proteins. Curr. Opin. Lipidol. 19, 441-447.

Ozeki, S., Cheng, J., Tauchi-Sato, K., Hatano, N., Taniguchi, H., and Fujimoto, T. (2005) Rab18 localizes to lipid droplets and induces their close apposition to the endoplasmic reticulum-derived membrane. J. Cell. Sci. 118, 2601-2611. 
Piver, E., Roingeard, P., and Pagès, J. (2010) The cell biology of hepatitis C virus (HCV) lipid addiction: molecular mechanisms and its potential importance in the clinic. Int. J. Biochem. Cell Biol. 42, 869-879.

Robenek, H., Hofnagel, O., Buers, I., Robenek, M. J., Troyer, D., and Severs, N. J. (2006) Adipophilin-enriched domains in the ER membrane are sites of lipid droplet biogenesis. J. Cell. Sci. 119, 4215-4224.

Roingeard, P. and Hourioux, C. (2008) Hepatitis C virus core protein, lipid droplets and steatosis. J. Viral Hepat. 15, 157-164.

Roingeard, P., Hourioux, C., Blanchard, E., and Prensier, G. (2008) Hepatitis C virus budding at lipid droplet-associated ER membrane visualized by 3D electron microscopy. Histochem. Cell Biol. 130, 561-566.

Singh, R., Kaushik, S., Wang, Y., Xiang, Y., Novak, I., Komatsu, M., Tanaka, K., Cuervo, A.M., and Czaja, M.J. (2009) Autophagy regulates lipid metabolism. Nature 458, 1131 1135 .

Sztalryd, C., Xu, G., Dorward, H., Tansey, J. T., Contreras, J. A., Kimmel, A. R., and Londos, C. (2003) Perilipin A is essential for the translocation of hormone-sensitive lipase during lipolytic activation. J. Cell Biol. 161, 1093-1103.

Szymanski, K., Binns, D., Bartz, R., Grishin, N.V., Li, W-P., Argawal, A.K., Garg, A., Anderson, R.G.W, and Goodman, J.M. (2007) The lipodystrophy protein seipin is found at endoplasmic reticulum lipid droplet junctions and is important for droplet morphology. Proc. Natl. Acad. Sci. USA 104, 20890-20895.

Targett-Adams, P., Chambers, D., Gledhill, S., Hope, G., Coy, J.F., Girod, A., and McLauchlan, J. (2003) Live cell analysis and targeting of the lipid droplet-binding adipocyte differentiation-related protein. J. Biol. Chem. 278, 15598-16007.

Tauchi-Sato, K., Ozeki, S., Houjou, T., Taguchi, R., and Fujimoto, T. (2002) The surface of lipid droplets is a phospholipid monolayer with a unique fatty acid composition. J. Biol. Chem. 277, 44507-44512.

Thiele, C. and Spandl, J. (2008) Cell biology of lipid droplets. Curr. Opin. Cell Biol. 20, 378385.

Wan, H., Melo, R. C. N., Jin, Z., Dvorak, A. M., and Weller, P. F. (2007) Roles and origins of leukocyte lipid bodies: proteomic and ultrastructural studies. FASEB J. 21, 167-178.

Welte, M. A. (2007) Proteins under new management: lipid droplets deliver. Trends Cell Biol. 17, 363-369. 
Welte, M. A. (2009) Fat on the move: intracellular motion of lipid droplets. Biochem. Soc. Trans. 37, 991-996.

Wolins, N. E., Brasaemle, D. L., and Bickel, P. E. (2006) A proposed model of fat packaging by exchangeable lipid droplet proteins. FEBS Lett. 580, 5484-5491.

Wolins, N. E., Quaynor, B.K., Schoenfish, M.J., Tzekov, A., and Bickel, P. E. (2005) S3-12, adipophilin, and TIP47 package lipid in adipocytes. J. Biol. Chem. 280, 19146-19155.

Zehmer, J. K., Huang, Y., Peng, G., Pu, J., Anderson, R. G. W., and Liu, P. (2009a) A role for lipid droplets in inter-membrane lipid traffic. Proteomics 9, 914-921.

Zehmer, J. K., Bartz, R., Bisel, B., Liu, P., Seemann, J., and Anderson, R. G. W. (2009b) Targeting sequences of UBXD8 and AAM-B reveal that the ER has a direct role in the emergence and regression of lipid droplets. J. Cell. Sci. 122, 3694-3702. 

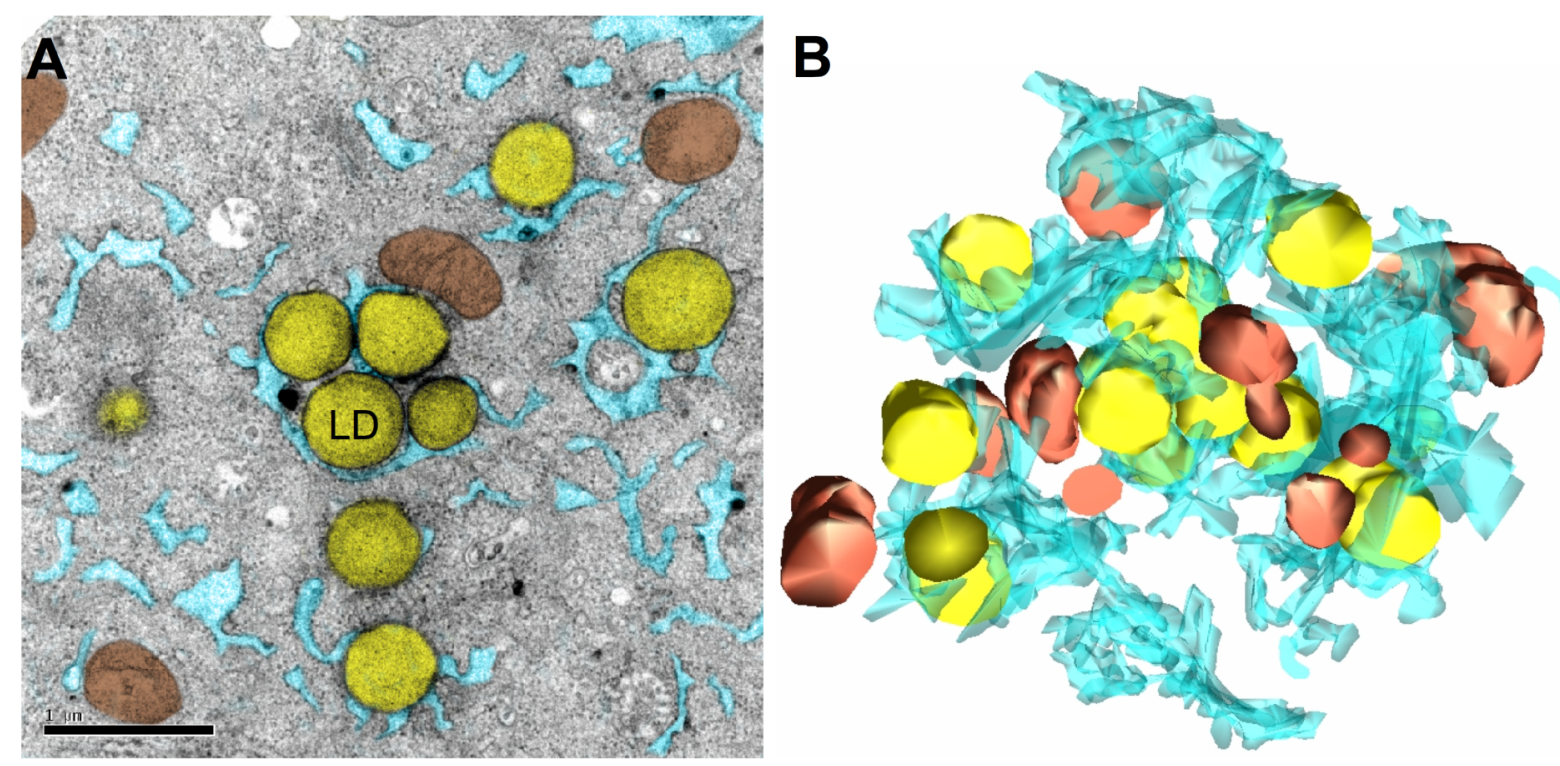

Figure 1. Three-dimensional reconstruction from serial ultrathin sections of a subcellular domain containing lipid droplets

(A) Sample of one (central) TEM ultrathin section of this subcellular domain, showing the LDs (yellow), ER (light blue), and mitochondria (brown). (B) View of a full reconstruction, using the same colour code, of this subcellular domain corresponding to 15 serial TEM ultrathin $(60-70 \mathrm{~nm})$ sections, showing that all LDs are tightly bound to smooth ER membranes. The LDs shown in these TEM photographs are from baby hamster kidney (BHK21) cells, and the cellular microdomain was reconstructed with IMOD software, as described elsewhere (Roingeard et al., 2008; Depla et al., 2010). Scale bar: 1 micrometre. A QuickTime movie of this 3D reconstruction is also provided as supplemental material online. 

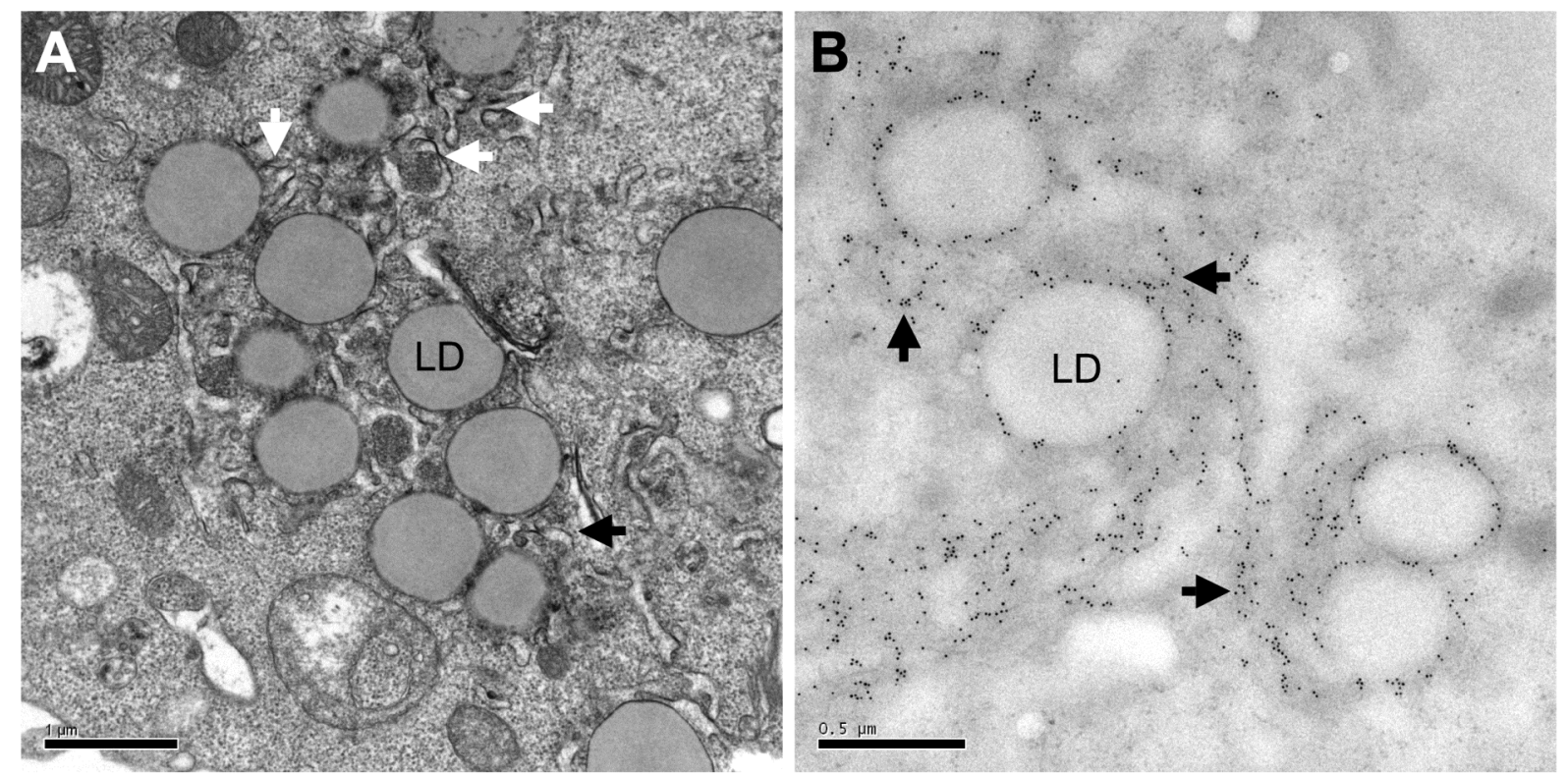

Figure 2. HCV core production induces the relocalisation, within a few hours, of lipid droplets to perinuclear areas

(A) On conventional TEM, these clustered LDs are connected to the convoluted electrondense ER membrane (arrows). (B) Freeze substitution TEM and immuno-gold labelling with a specific monoclonal antibody shows the presence of large amount of HCV core protein in these convoluted ER membranes linked to LDs (arrows) and the membranes surrounding LDs. The LDs shown on these photomicrographs are from BHK-21 cells (see Depla et al., 2010 for details of the materials and methods). Scale bars: 1 micrometre (A), 0.5 micrometre (B). 


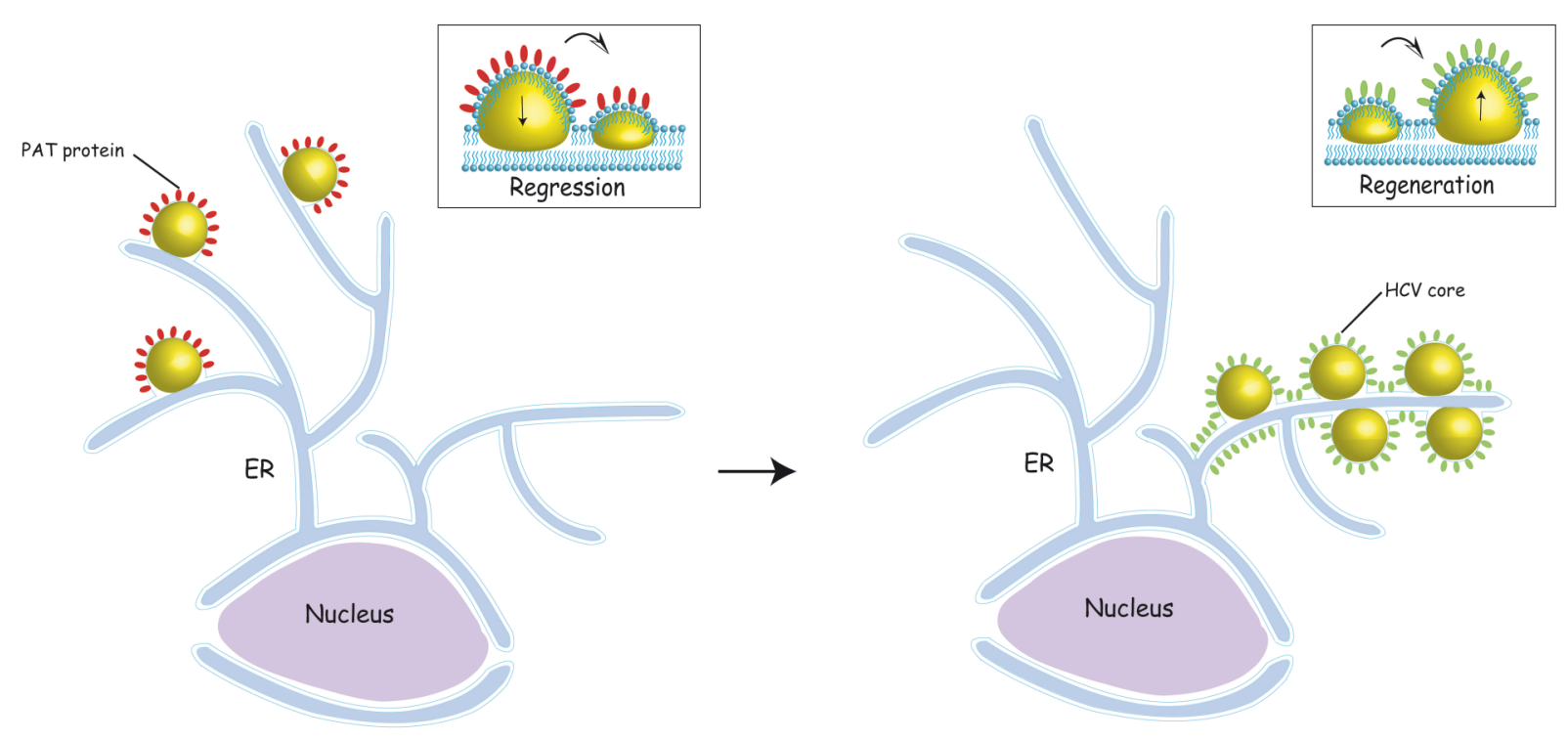

Figure 3. Possible mechanisms of LD redistribution induced by the HCV core protein

LDs that have initially emerged from the ER bilayer as a lens-shape mass of neutral lipids remain attached to the ER membrane to form a round structure surrounded by a phospholipid monolayer containing PAT/PLIN proteins. These LDs dispersed throughout the cell could regress towards ER membranes and regenerate in distant specific ER membranes domains enriched in $\mathrm{HCV}$ core protein. The $\mathrm{HCV}$ core protein may contribute to curve the $\mathrm{ER}$ membrane to mediate the LD budding. The LD regression/regeneration hypothesis provides a comprehensive model accounting for the replacement of a host cell PAT/PLIN protein by the $\mathrm{HCV}$ core protein at the surface of newly synthesised LDs. The structures depicted in this model are not drawn to scale. 